Jear after, one seren months, two six months, three four months, one three months; and before the other two ceased to be under observation, a second dose was given by way of precaution, as it was to all the patients when the head was not found, without any tænia coming away with the stool.

Three required two doses of the drug; in one of these three some yards of tænia were expelled by the first dose; for two months after this no joints were found in the stools, then a few appeared, and a second dose was given, and was followed by the expulsion of nine yards of trenia; the patient continued well two years after this. In the second case, three yards were expelled by the first dose, and a month after, five feet by a second dose; at the expiration of four months and a-half the patient continued well; in the third case five and a-half yards of tronia were expelled by the first dose, and seven yards by the second, given two months after the first.

These doses were required in two cases. The first dose of the oil, however, given to one of these cases was not of good quality. In one of the two, three days elapsed between the first and second dose, and four hours between the second and third. In the other, two days elapsed between the first and second dose, and one between the second and third. In both cases the head was obtained.

In one case, viz., that of a child fire years and six months old, between the 15th of July and the 4 th of August inclusive, five doses of castor oil, and as many of oil of male fern, were administered, without a decided effect-a few joints of tænia only being expelled. On the 17th of August, twenty grains of the extract of male fern,* obtained from Duncan and Flockhart, of Edinburgh, were given without effect. On August 23rd, one pint of infusion of pumpkin seeds; on September 1st, decoction of pomegranate; and on September 5th, infusion of kousso; all produced copious evacuations, but no tapeworm. The child now left the hospital. In November he was readmitted, and during my absence was treated with success by my friend Dr. Ballard with the oil of male fern. This time the child was kept for forty-eight hours with little if any food, before the oil was given. The child was free from tapeworm some months after he left the hospital.

One man took the oil two or three times without any good effect, but then large quantities of solid fæces were discharged from its action; and before it could be administered in a more effectual manner, the patient escaped observation.

Among those cured by a single dose, and well two years afterwards, was one man who had taken kousso three times, and oil of turpentine twice. Several of the others had taken turpentine and other remedies with permanent good effect. In three cases (children) the patients rejected the oil by romiting; with one exception, all admitted that it was much less nauseous than castor oil. In no case did it cause griping or other unpleasant symptom. The shortest time after taking the oil in which the worm was expelled was half an hour; the longest twelve hours; the ordinary time four hours. A large quantity of tenacious yellow mucus was usually expelled either with or before the worm, and often, also, when no worm was present, as when the oil was given to ascertain that no worm remained, the head not having been found.

In no case was the worm alive when expelled, and in no case was it expelled entire.

The mode of administering the oil of male fern, I would recommend, after the experience $I$ have had of it, is as follows:-

For an adult, two pills may be taken at bedtime, containing three grains of calomel and eight of compound colocynth pill-the following morning a dose of castor oil. $A$ little broth only should be given till the bowels have been thoroughly cleared out. As soon as that object is effected, one drachm and a-half of oil of male fernt is to be

- The preparation recommended by Dr. Christison.

+ The oil of male fern is prepared with great care by Mr. Squire, of Oxford Strect. given on an ounce of some aromatic water; and the doce of oil of male fern is to be repeated in sir hours, if the first dose has not proved effectual before the expiration of that time.

For a child, calomel and jalap may be substituted for the colocynth and calomel. The dose of the oil of male fern must be as large for the child as for the adult, seeing that its action is on the parasite and not on the patient. I have never seen any unpleasant results follow its employment in the child.

\section{ON ARSENIC-EATING.}

By W. B. Kesteven, Esq., F.R.C.S.

Soxe correspondence respecting the truth of the alleged practice of arsenic-eating in Styria was published in the Assooration Jodrnal last year. * I have subsequently been at some trouble to investigate the grounds on which this story has rested-a story so directly opposed to all previous experience of the effects of arsenic on the human system, and hitherto so unsupported by authentic facts, as to have met with incredulity at the hands of the most distinguished toxicologists, British and foreign. Inquiry soon showed that, up to the time when this investigation was commenced, all the accounts of the "arsenic-eaters" that had been laid before the British public had been derived, at second hand, from Dr. Von Tschudi's paper in the Wiener Medizinische Wochenschrift for October 11 th, 1851.

Dr. Von Tschudi's paper, then, constitutes the basis of the late Professor Johnston's romance, $t$ and of certain articles in Chambers's Journal. I have, in the first place, submitted a literal translation of the unmutilated paper, with a view to a subsequent examination and comparison of its statements, and of the information more recently obtained from original sources, with that of the pretended impunity of arsenic eating, by the popular writers above referred to. Not to forestal our conclusions, it may here be simply asserted that arsenic is still a poison, even in Styria; and that it cannot eren there be trifled with without the gravest consequences. In a medico-legal point of view, which is that from which this subject must be regarded as having more especially called for investigation, it is believed by the writer that it will be shown to be useless as a means of defence in criminal proceedings.

TRAKSLATION OF DR. VON TSCHUDI's PAPER.

"In some districts of Lower Austria and Styria, especially in the mountainous districts of Hungary, $\ddagger$ there prevails, especially among the peasantry, the extraordinary practice of arsenic eating. It is procured under the name of Hedri (Hidri, Hidrich-hütterausch), $\S$ from the hawkers of herbs, or pedlars, who in their turn purchase it of the workpeople in the Hungarian glass-houses, or of farriers (Viehüraten), or of quacks.

"Poison-eaters have a twofold object in their hazardous indulgence. On the one hand, they look to obtain a fresh healthy aspect, and a certain degree of obesity. It is hence very frequently taken by peasant youths and girls, in order to promote reciprocal liking; and it is, in fact, remarkable with what favourable results their views are attended. The jurcnile poison-eater shortly exhibits a very blooming complexion, and a strikingly healthy exterior. I here cite one from among sereral instances. H., a healthy but spare and pale dairymaid, belonging to a farm-house at Pfarre, had a lover whom she wished still more to captivate by her personal appearance. She had recourse, therefore to the notorious means, and took arsenic several times a week. The desired effect ras produced, and, after a few months, she had become stout, rosy-cheeked, and altogether

- See numbers for November 2, 8, 16,23, and 30,1855.

+ See "The Chemistry of Commor

Dr. Fon Tsclind: adds in a foot note:- "How far this abnse prevails, I canot rith certainty determine; and omphatically remark, that $I$ hore oafy speak of the districts known to me."

speak of the districts known to me."

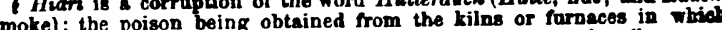
cobalt ore is exposed to fire, and which are known as "poison huts". 
quite to hor lorer's satisfaction. To heighten still further the effects, she imprudently augmented her dose of arsenic, and foll a victim to her vanity : she died a painful death, from the action of the poison.

"The number of deaths in consequence of taking arsenic in too large or frequent doses is by no means trifling, more particularly among young people. Every curate in the districts where this abuse prevails is often made acquainted with such cases; and the inquests which I have attended have furnished me with similar results. Whether from fear of the law, which forbids the unrestricted sale of arsenic, or whether it be the voice of conscience that reproaches them with the wrongfulness of the practice, the poison-eaters keep their use of such dangerous substance a profound secret. For the most part, it is only the confessional or the deathbed that lifts the veil of secresy.

"The second object which the poison-eaters have in view is to render themselves, as they express it, more airy (liftiger) or lighter-to facilitate respiration in ascending mountains. When they have to undertake a long journey up the mountains' sides, they put a crumb of arsenic into their mouths, and allow it gradually to dissolve. 'The operation is surprising, and they will ascend with facility heights which previously they could only climb with great difficulty in breathing.*

"According to their own confessions, the dose with which the poison-eaters begin is a portion about the size of a lentil seed, which would in weight be about half a grain. This dose is taken a few times weekly, in the morning, fasting, and is continued a long time, until they get used to it; this is cautiously increased, in proportion as the accustomed operation subsides. A peasant, $R-$, of the parish of $A-g$, a vigorous man of 60 years of age, who had always enjoyed good health, is at the present time taking about four grains for each dose. For more than forty years he has followed this habit, which he inherited from his father, and has transmitted to his son.

"It is to be borne in mind that neither in this case nor in many others has the slightest trace of arsenical poisoning been remarked; that the symptoms of chronic arsenical poisoning do not appear in those who adapt the dose to their constitutions, and to the degree to which they have become accustomed to its action. It must not be omitted to be mentioned, that if, from accidental want of arsenic, or from any other cause, an individual is obliged to abstain, symptoms of illness supervene, having the closest resemblance to those of arsenical poisoning. There is seen especially a great dislike and indifference to those around; anxiety as regards some persons; indigestion in its various forms; loss of appetite; a constant feeling of the stomach being overloaded; vomiting of mucus in the morning, with increased secretion of saliva ; a sense of burning, extending from the pylorus to the throat; spasmodic contraction of the pharynx; griping pains; constipation; and difficulty of breathing. The only means of relieving all these symptoms consists in a speedy return to the practice of arseniceating.

"According to the latest inquiries among the inhabitants of this district, the arsenic-eater becomes such only through indulgence, like the oriental opium-eater, the Indian and Polynesian betel-chewer, and the Perurian cocoa-chewer; but, once having established the habit, it becomes a necessity.

"Similar with that of arsenic-eating is the practice of eating corrosive sublimate. I remember onc case, stated to be authentic by the English ambassador in Turkey, of a confirmed opium-eater in Brussa, who also daily took the enormous quantity of forty grains of corrosive sublimate with his opium. I have often met with sublimate-eaters in the mountainous regions of Peru; the practice is still more common in Bolivia, where the corrosive sublimate is openly sold in the markets to the Indians.

"I need scarcely here state that the use of arsenic is very extensive in Vienna, particularly among grooms and

\footnotetext{
- Dr. Tachudi has observed a similar result in cases of asthma, when the
} patient has been taking Fowler's solution. coachmen. They sprintle a full pinch of the powder upon the oats, or a piece the size of a pea is tied up in a linen bag, and fastened to the bit when the horse is bridled, and so is gradually dissolved by the animal's saliva. The shining, round, and good look of most fine carriage-horses, and more particularly the approved fosming at the mouth, is the result of the action of arsenic, one of the effects of which is to promote salivation. It is a very general custom in the mountain districts, that, when a horse must draw a heavy load up a steep hill, the servant mixes a dose of arsenic with his latest feed.* This practice is pursued through many years without harm to the horse; but, in the event of his passing into the hands of a master who does not permit the use of arsenic, he loses flesh, activity, becomes dull, and the richest fodder will no longer suffice to give its former appearance." $†$

The preceding is the whole of the much quoted statements of Dr. Von Tschudi. In a following communication, I propose to examine the English versions of the same story, and to notice the reception it has met with at the hands of those scientific men who are best qualified to judge of its credibility.

[To be continued.]

\section{CONSIDERATIONS RESPECTING THE OPRRATION OF MALARIA ON THE HUMAN BODY.}

By C. HandFiend Joses, M.B., F.R.S., Assistant-Physician to St. Mary's Hospital.

[Continued from page iol.]

7. I will now attempt to inquire whether there be anything common to these disorders I hare reviewed-whether there can be discerned any pathological feature of family resemblance among them. Such I believe may be found, exclusive of the efficient cause which I have supposed them all to possess. It appears to me that the diseases above enumerated fall naturally into four classes; viz., fevers; affections of the nerves or nervous centres; inflammations; and secretion-fuxes. These certainly, taking well marked typical instances, appear to differ widely enough from each other; yet I believe it will be very possible to prove a close degree of connexion between them.

a. Fevers. It is undeniable that the chief and most constant phenomena met with in ferers are the prostration of strength and of the mental faculties, and the alteration of the temperature of the body. Galen defined ferer as calor proter naturam; and Dr. Parkes considers that the accuracy of this phrase is now fully recognised. Virchow also remarks, that this preternatural heat is the substance of fevers. This opinion rests on observations made with the thermometer, which show that the temperature of the blood is rapidly rising even during the existence of the rigor, as in the cold stage of an ague. Indeed, the skin, which is emptied of blood by the constriction of its ressels, is colder than usual; but the state of the internal organs is different.

It will be observed that I have spoken above of the alteration of the temperature as a capital febrile phenomenon, not merely of its increase. No doubt the latter is the more generally marked and striking, and suggested the terms auperds, and kavioos, and febris: but I think the occasional lowering of the temperature should not be left out. of view altogether. No doubt its chief cause is the absence of blood from the part; but some doubt may exist whether there may not be another cause also, especially in the algide conditions, as of pernicious ague and cholera,

" Horsedealers frequently administer from a quarter of a pound to half s pound of shot to broken-winded horses before taking them to the horsea porad. They to the breathingmarket. They do this to form of drops." (Trechudi.)

of drops." (Techudi.) "The + "The quantity of areenic given by servants is onen the large, and the carelessuess with which it is kept culpablo. As inch as three quarters of pound has been found in the possession of a peasant. In another instance, a peasant mixed a portion, of the 